\title{
Beware erysipelas: renal disease is just around the corner
}

\author{
Alfonso Lagi, ${ }^{1}$ Filippo Lagi ${ }^{2}$ \\ ${ }^{1}$ Emergency Department, Santa Maria Nuova Academic Hospital; ${ }^{2}$ Infectious Diseases, Careggi Hospital, Florence, Italy
}

\begin{abstract}
We describe a case of erysipelas caused by Streptococcus Group G to draw attention to organ and systemic complications that may be associated with this disease. Group G streptococcal infection affected a 70-year old woman following a small skin wound at the base of her second left toe. On admittance to the emergency department, the patient's urine was dark from macrohematuria. She later developed septic shock. Cutaneous and renal symptoms were kept in check with antibiotic therapy, and she fully recovered from the septic shock after receiving specific therapies. This case shows that erysipelas is not just a disease of the skin and soft tissues, but one that may be associated with organ diseases and systemic complications. The patient completely recovered from both the cutaneous and kidney pathologies after antibiotic therapy.
\end{abstract}

\section{Introduction}

Erysipelas is an infrequent infection of the skin and soft tissues. Streptococcal etiology is more common in rural areas and in females, and the average age of onset is approximately 60 years. Patients often have comorbidities such as diabetes mellitus type 2 , venous insufficiency in the leg and chronic lymphoedema, leg ulcers, and chronic renal failure. All these conditions favor local infections or are capable of compromising the immune system. ${ }^{1}$

The majority of cases limited to the skin have a favorable outcome. Sometimes, however, erysipelas is not limited to a skin disease. It is a disease that can engage and damage other organs or may cause sepsis. This case is unusual because, in addition to skin symptoms, the patient also presented with kidney complications and sepsis. This disease should always be treated with appropriate therapy at first presentation, and the patient should be closely followed, even in a hospital setting, if necessary, until clinical remission.

Correspondence: Alfonso Lagi, Emergency Department, Santa Maria Nuova Academic Hospital, Florence, Italy Tel. +39.338.6326900 - Fax: +39.055.6938386

E-mail: alfonso.lagi1@tin.it

Key words: bullae, blistering erysipelas, cellulitis, erysipelas, skin infection.

Conflict of interest: the authors declare no conflict of interests

This work is licensed under a Creative Commons Attribution NonCommercial 3.0 License (CC BY-NC 3.0).

CCopyright A. Lagi and F. Lagi, 2013

Licensee PAGEPress, Italy

Italian Journal of Medicine 2013; 7:193-195

doi:10.4081/itjm.2013.193

\section{Case Report}

A 70-year old woman without any underlying disease complained of high fever, chills and muscle aches. After three days she had erythema and pain in her right leg, and dark urine, and went to the Emergency Department.

During the general objective examination, the patient had a fever of $39^{\circ} \mathrm{C}$, was overweight (body mass index: $28 \mathrm{~kg} / \mathrm{m}^{2}$ ), was hemodynamically stables, with a respiratory rate of $20 \mathrm{bpm}$, normal heart activity, heart rate 98', blood pressure 120/75 $\mathrm{mmHg}$, free lung fields, no pain or soreness of the abdomen, and normal arterial pulse.

A local examination revealed edema associated with erythema in the patient's left leg with sharp demarcation except in her big toe (Figures 1 and 2). She had bleeding blisters on the back of her foot and heel, and small ulcerated lesions at the base of her second finger (Figure 3). The patient recalled getting these injuries while gardening one week prior to admission.

Blood tests were abnormal: white cell count was $21 \times 10^{9} / \mathrm{L}$ with neutrophilia ( $85 \%$ ), and an erythrocyte sedimentation rate of $45 \mathrm{~mm} / \mathrm{h}$.

Urine analysis and sediment showed proteinuria $110 \mathrm{mg} / \mathrm{dL}$, microscopic hematuria 3+, leukocyturia $1+$, erythrocytic casts, epithelial casts, and significantly higher amounts of erythrocytes, leukocytes, and tubular epithelial cells/20 high power field.

Hemocultures taken at three time points (one every $30 \mathrm{~min}$ ) were negative. Group G streptococcus was identified by microscopic examination and cultivated from liquid taken from the blisters.

Treatment with antibiotics was started as follows: beta-lactam antibiotics (ceftriaxone) once daily and fluoroquinolones (levofloxacin) once daily. The patient also received anticoagulants (fondaparinux 7.5 $\mathrm{mg}$ once daily), as well as methylprednisolone 16 
$\mathrm{mg}$ /day. She also received saline therapy $120 \mathrm{~mL} / \mathrm{h}$, and acetaminophen as needed. The injury was dressed with antiseptic and grease gauze.

On Day 3, the patient's fever subsided then disappeared. At that time, the patient presented with rhythmic tachycardia (125 bpm) and low blood pressure, contraction of diuresis (anuria for $4 \mathrm{~h}$ ), and lactic acidosis $\left[\mathrm{pH} 7.35 ; \mathrm{PaO}_{2} 98 \mathrm{mmHg} ; \mathrm{PaCO}_{2} 31\right.$ $\mathrm{mmHg}$; $\mathrm{BE}-8$; lactic acid $6.1 \mathrm{mmol} / \mathrm{L}$ (normal value $1 \mathrm{mmol} / \mathrm{L})]$. The patient was diagnosed with septic shock and was treated with a massive infusion of liq-

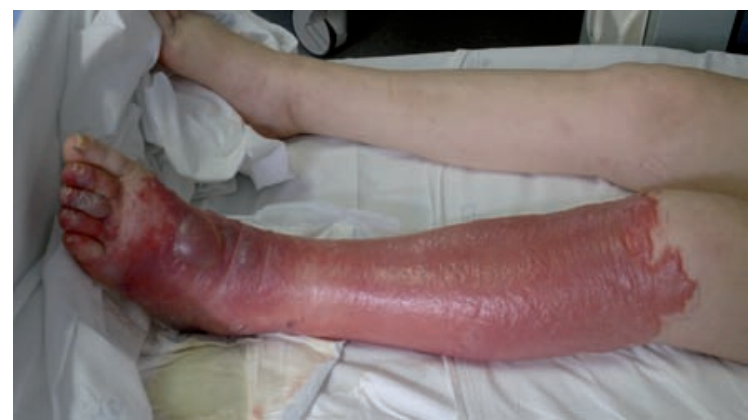

Figure 1. Blisters were present on the patient's right leg and the base of her second finger was infected.

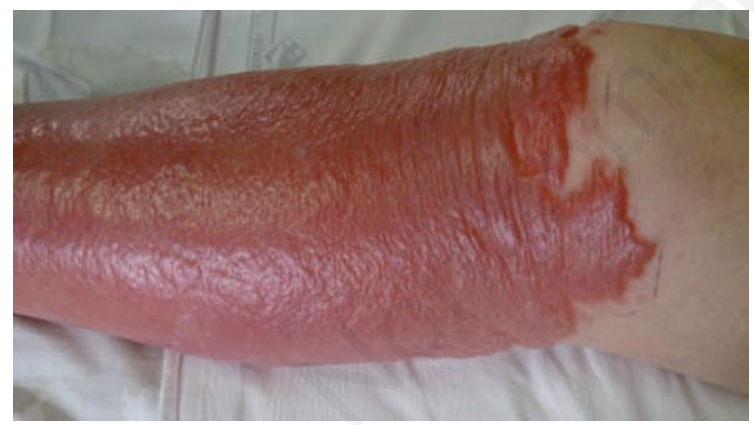

Figure 2. The clear demarcation of erythema and edema was particularly evident.

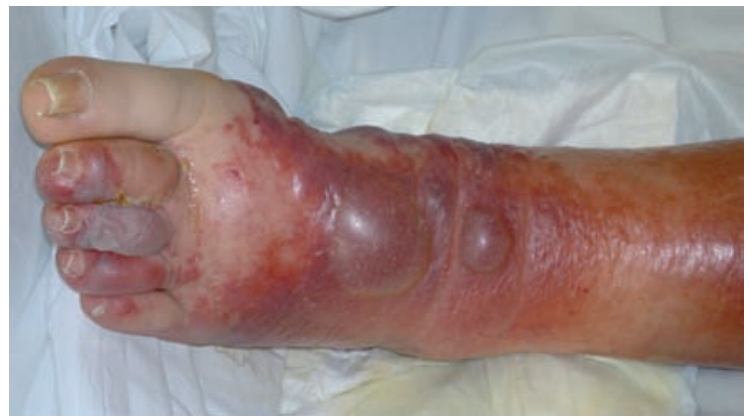

Figure 3. Erythema and edema. uids $(500 \mathrm{~mL}$ over $30 \mathrm{~min}$ then $3500 \mathrm{~mL}$ over the next $4 \mathrm{~h}$ ). The patient also received $500 \mathrm{mg}$ hydrocortisone per bolus followed by prednisone $(1 \mathrm{mg} / \mathrm{kg}$ for three days); finally, therapy with vancomycin $(500 \mathrm{mg} / 6 \mathrm{~h})$ was started. The clinical picture normalized within $12 \mathrm{~h}$.

The patient was discharged after eight days with a prescription for antibiotics and other medications. After one month, the patient was in good clinical condition and urine samples had normalized. The patient gave her consent to the therapy, and to the publication of the case report.

\section{Discussion and Conclusions}

This case illustrates how erysipelas, commonly seen as a disease of the skin, can have possible systemic involvement, even in low-risk subjects without comorbidities. In patients with erysipelas, $47 \%$ are asymptomatic for urinary abnormalities, $11 \%$ have isolated proteinuria, $13 \%$ have proteinuria associated with hematuria, and $23 \%$ have isolated hematuria. Patients with nephrotic or nephritic syndrome have been reported. ${ }^{1,2}$ Two patients with acute renal failure and streptococcal erysipelas had renal biopsies and had acute interstitial nephritis with a predominantly mononuclear infiltrate. A course of betalactam antibiotics without steroid therapy was followed by complete recovery of renal function. Some cases of acute interstitial nephritis related to infection are erroneously attributed to antibiotic hypersensitivity. ${ }^{3} \mathrm{Be}-$ cause of the difficulty of obtaining bacterial cultures from patients with cellulitis and erysipelas, the microbiology of these common infections remains incomplete. For erysipelas, $4.6 \%$ of 607 patients had positive blood cultures of which $46 \%$ were Streptococcus pyogenes, $29 \%$ were other beta-hemolytic streptococci, $14 \%$ were Staphylococcus aureus, and 11\% were Gram-negative organisms. ${ }^{4-6}$ Pain disproportionate to the physical findings, violaceous bullae, cutaneous hemorrhage, skin sloughing, skin anesthesia, rapid progression and gas in the tissue, and the presence of signs of systemic toxicity such as body temperature over $38^{\circ} \mathrm{C}$ or under $36^{\circ} \mathrm{C}$, heart rate over 100 beats per minute (bpm), and hypotension (systolic blood pressure below $90 \mathrm{mmHg}$ or 20 $\mathrm{mmHg}$ below baseline) may also be indicative of a severe soft tissue infection.?

Patients with the first signs of erysipelas should be given adequate treatment and be closely monitored.

\section{References}

1. Pereira de Godoy JM, Galacini Massari P, Yoshino Rosinha M, et al. Epidemiological data and comorbidities of 428 patients hospitalized with erysipelas. Angiology 2010;61:492-4.

2. Legoupil D, Kupfer-Bessaguet I, Le Brun K, et al. He- 
morrhagic erysipelas of the lower limbs: 5 cases. Ann Dermatol Venereol 2004;131:833.

3. de Godoy JM, Irikura MK, de Moura Álvares R, Quintino E. Association of erysipelas with acute renal failure. Int Urol Nephrol 2011;43:917-8.

4. Celestin R, Brown J, Kihiczak G, Schwartz RA. Erysipelas: a common potentially dangerous infection. Acta Dermatovenerol Alp Panonica Adriat 2007; 16:123-7.

5. Ligtenberg G, Blankestijn PJ, Koomans HA.
Erysipelas: not always innocent. Neth J Med 1993; 43:179-82.

6. Celestin R, Brown J, Kihiczak G, Schwartz RA. Erysipelas: a common potentially dangerous infection. Acta Dermatovenerol Alp Panonica Adriat 2007; 16:123-7.

7. Bomke AK, Vagts DA, Podbielski. Toxic-shock-likesyndrome caused by beta-hemolysing group G streptococci in a multimorbid patient with erysipelas. Dtsch Med Wochenschr 2006;131:263-6. 